https://helda.helsinki.fi

\title{
Predicting the direction of US stock markets using industry returns
}

\author{
Pönkä, Antti Harri Miikka
}

2017

Pönkä , A H M 2017 , ' Predicting the direction of US stock markets using industry returns ' , Empirical Economics , vol. 52 , no. 4 , pp. 1451-1480 . https://doi.org/10.1007/s00181-016-1098-0

http://hdl.handle.net/10138/303630

https://doi.org/10.1007/s00181-016-1098-0

acceptedVersion

Downloaded from Helda, University of Helsinki institutional repository.

This is an electronic reprint of the original article.

This reprint may differ from the original in pagination and typographic detail.

Please cite the original version. 


\title{
Predicting the direction of US stock markets using industry returns
}

\section{Harri Pönkä}

the date of receipt and acceptance should be inserted later

\begin{abstract}
In this paper, we examine the directional predictability of US excess stock market returns by lagged excess returns from industry portfolios and a number of other commonly used variables by means of dynamic probit models. We focus on the directional component of the market returns because, for investment purposes, forecasting the direction of return correctly is presumably more relevant than the accuracy of point forecasts. Our findings suggest that only a small number of industries have predictive power for market returns, meaning that we find little evidence of stock markets reacting with a delay to information contained in industry returns. We also find that the binary response models outperform conventional predictive regressions in forecasting the direction of the market return. Finally, we test trading strategies and find that some of the industry portfolios do contain information that can be used to improve investment returns.
\end{abstract}

Keywords Industry excess return, Sign prediction, Probit model, Forecasting

JEL: C25, C53, C58, G17

H. Pönkä

Department of Political and Economic Studies, University of Helsinki, P.O.Box 17, FIN-00014, Finland

Tel. +358-50-3183897, E-mail: harri.ponka@helsinki.fi 


\section{Introduction}

There is a vast literature in financial economics focusing on the prediction of stock returns using publicly available information. The topic is of interest from many perspectives. From an empirical point of view, these studies provide information on the factors driving stock markets. The potential for increased returns through better forecasts has kept the topic current among financial practitioners. From a theoretical perspective, studies on stock return forecasting can be seen as tests of asset pricing theories. For a comprehensive and up-to-date overview of the literature on the different variables, methodologies, and theories used in the research on stock return predictability, we refer to Rapach and Zhou (2013).

As a reaction to prevailing anomalies in stock markets, there is a large number of studies that relax the strict assumptions of rationality, perfect markets, and unlimited information processing power of investors. Among these studies a growing literature on behavioural theories aim to explain some aspects of investor behaviour. One of these is the unified theory of underreaction, momentum trading, and overreaction in asset markets, proposed by Hong and Stein (1999). This theory is based on the idea of gradual diffusion of information across investors, which causes prices to underreact in the short run, making it possible for momentum traders to profit from trend chasing. Focusing on industries is potentially an interesting way to study the gradual diffusion of information, since investors with limited information processing capabilities might not be able to follow markets as a whole, but instead focus on a few industries. This issue is addressed in by Hong, Torous, and Valkanov (2007), who study the predictive ability of industry portfolios for excess stock market returns. Their findings from predictive regressions suggest that a number of industries lead the stock markets in the US and eight largest non-US markets, which can be seen as evidence in favor of information diffusing slowly within markets.

The purpose of this study is to extend the research on the predictive power of industry portfolio returns on excess stock market returns. However, in contrast to the previous literature, we do this by examining whether the direction of stock markets can be predicted by lagged returns of industry portfolios. Our main motivation is to see whether the previous findings of Hong et al. (2007), among others, hold in the dynamic probit models of Kauppi and Saikkonen (2008). These models are similar in spirit to the autologistic models of Rydberg and Shephard (2003), and Anatolyev and Gospodinov (2010).

We focus on the directional component of the excess market returns because, based on a number of previous empirical results, it can be argued that for investment purposes predicting the direction of return correctly is more relevant than the accuracy of point estimates. Already in Merton's (1981) classic market timing model, fund managers are interested in the sign rather than the actual value of the return when determining their asset allocations. Furthermore, there is some evidence that classification-based models, such as binary response models outperform traditional predictive regression models (also referred to as 'level models' below) in terms of profitability of investment strategies built on their forecasts (see Leung, Daouk, and Chen (2000)). The dynamic probit models have been used in a similar application by Nyberg (2011), who finds that six-month-ahead recession forecasts perform well as predictors of the direction of the stock market in the US.

Our in-sample results indicate that only two to eight out of 34 industries lead the stock market in our application, depending on the model specification used. Hence, we find only weak evidence in favor of gradual diffusion of information across asset markets. An interesting finding is that the lagged term structure and the lagged growth of the three-month interest rate captures much of the information contained in the excess returns on industry portfolios. Our findings also suggest that information from a small number of industry portfolios is useful in out-of-sample forecasting, and may be used to increase profitability of trading strategies. This implies that the some of the industry portfolios do contain information that can be useful for directional predictability of excess returns, which is relevant in terms of market timing, but overall their predictive power of remains rather low.

One of our key findings on the performance of the different types of models is that the dynamic probit models outperform the conventional predictive regression model in terms of out-of-sample forecasting accuracy of the direction of the excess stock market returns, which clearly supports the use and further examination of these models. Moreover, although the dynamic extensions of the probit model yield the best in-sample fit, the more parsimonious static probit model performs better out-of-sample.

This paper is organized as follows. In the following section, we summarize findings of Hong et al. (2007) and related research. In Section 3, we discuss the methodology, and in Section 4 we introduce the data. We are primarily interested in testing for the presence of gradual diffusion of information across markets, and this is the purpose of the in-sample analysis in Section 5. In addition, we are interested in comparing the forecast performance of the predictive regressions and dynamic probit models. This is the focus of Section 6 where we report the out-of-sample forecasting results. In Section 7, we experiment with models using daily frequency data. Finally, in Section 8, we conclude and discuss possible extensions. 


\section{Previous literature on industry returns}

As pointed above, the study most closely related to ours, is that of Hong et al. (2007), who study the predictive ability of industry portfolio returns for monthly US stock market returns in 1946-2002. They also examine the corresponding predictive relationship in Japan, Canada, Australia, the UK, Netherlands, Switzerland, France, and Germany for a shorter period running from 1973 to 2002. The hypothesis behind the analysis is that the information originating from certain industries, in general, diffuses to the stock market only with a lag. This hypothesis is based on the assumptions that news travels slowly across markets, and that investors have limits to the amount of information they can process, meaning that most of them can only follow a limited amount of industries.

Hong et al. (2007) consider the following predictive regression for each industry portfolio separately:

$$
R E_{t}=\alpha_{i}+\lambda_{i} R_{i, t-1}+A_{i} Z_{t-1}+e_{i, t}
$$

where $R E_{t}$ is the excess return on the market portfolio at time $t, R_{i, t-1}$ is the excess return on industry portfolio $i$ at time $t-1, Z_{t-1}$ is a vector of control variables, and $e_{i, t}$ is the error term. The control variables are used as proxies for time-varying risk and include variables, such as inflation and the lagged excess market return $R E_{t-1}$. Model (1) leads to two testable hypotheses of the predictive power of industry portfolios for the whole stock markets and market fundamentals. With the main emphasis being on the US markets, they find that over the period 1946-2002, the excess returns in 14 out of 34 industries, including commercial real estate, petroleum, metal, retail, financial, and services, can predict market movements by one month. A number of other industries, such as petroleum, metal, and financial, can forecast the market as far as two months ahead. Even after including a variety of well-known proxies for risk and liquidity as well as lagged market returns in the vector $Z_{t-1}$, the predictability of the market by these 14 industry portfolios remains statistically significant.

A secondary goal of Hong et al. (2007) was to analyze the hypothesis that the ability of an industry to forecast the market is related to its ability to forecast changes in market fundamentals such as industrial production growth or changes in other indicators of economic activity. Their results on the predictability of industrial production growth by industry returns indicate that the same industries that have predictive power for the stock market in the US also predict industrial production growth. In nine industries predictability turns out to be statistically significant at the 5 percent level and in a further twelve at the 10 percent level. The mining, petroleum, and metal industries forecast the market and industrial production with a negative coefficient, whereas industries such as retail and financial have a positive coefficient.

Besides Hong et al. (2007), the predictive power of asset portfolios on aggregate market returns and other economic variables has been discussed in a number of studies, albeit the literature is scant. Moskowitz and Grinblatt (1999) study the momentum effect of industries and find that investment strategies based on buying previously profitable industries and selling previously losing industries turn out to be highly profitable. Lamont (2001) studies economic tracking portfolios, which are portfolios of assets that lead economic variables. His results suggest that monthly returns on stocks and bonds are useful in forecasting post-war US output, consumption, labor income, inflation, stock returns, bond returns, and Treasury bill returns. These findings are in line with those of Hong et al. (2007) in that industry portfolios can track both excess market returns as well as economic variables, such as inflation, growth in industrial production, and consumption growth. In a study focusing on a single industry, Cole, Moshirian, and Wu (2008) study the relationship between the financial industry stock returns and future GDP growth. They analyze data from 18 developed and 18 emerging markets using dynamic panel techniques and report a positive significant relationship between bank stock returns and economic growth. Furthermore, Menzly and Ozbas (2010) study the gradual diffusion of information in stock markets by analyzing the cross-predictability of stock returns from industries that have a supplier-customer relationship.

\section{Methodology}

In this paper, our aim is to predict the direction of US stock markets using lagged excess returns from industry portfolios. To this end, we use two types of models. Predictive regression models, such as the one presented in equation (1), are commonly used to study the statistical significance of potential predictors of excess stock market returns. We also employ these models in order to compare the directional predictive power of these so-called level models with dynamic binary response models. In this sense, we follow the work of Leung et al. (2000) who compare classification-based models and predictive regressions in forecasting stock indices. However, our work differs from theirs by focusing on the potential predictive power of industry returns and using dynamic probit models proposed by Kauppi and Saikkonen (2008), whose empirical 
application was related to forecasting US recessions. Given the binary nature of the NBER classification of expansions and contractions, recession forecasting has been a popular application of these models (see e.g. Nyberg (2010) and $\mathrm{Ng}(2012)$ ).

Our application is somewhat different, as we observe the actual values of returns and not only the direction. However, previous findings have suggested that the directional predictability is more important than mean predictability for building successful trading strategies. Christoffersen and Diebold (2006) show that, given the volatility dynamics in stock returns, one can find sign predictability even in the absence of mean predictability. Nyberg (2011) has a similar application to ours as he uses dynamic probit models to forecast the direction of the US stock market. A main focus in his paper is to use recession forecasts as an explanatory variable in the forecast for the sign of the excess stock return and to compare different model specifications in this framework. The main difference to our paper is the use of different predictors.

\subsection{Binary Response Models}

A key idea in our application of the binary response models is that the excess stock market return is transformed into a binary sign return indicator $y_{t}$ that is used as the dependent variable:

$$
y_{t}=\left\{\begin{array}{l}
1, \text { if the excess return is positive } \\
0, \text { otherwise }
\end{array}\right.
$$

We denote a vector of explanatory variables as $x_{t}$, which in our case includes returns from industry portfolios and commonly used market predictors. These variables will be discussed in more detail in Section 4 . The information set at time $t$ is given by $\Omega_{t}=\sigma\left[\left(y_{s}, x_{s}\right), t \geqslant s\right]$. Now, $y_{t}$ conditional on $\Omega_{t-1}$, follows a Bernoulli distribution

$$
y_{t} \mid \Omega_{t-1} \sim B\left(p_{t}\right) .
$$

If we denote the conditional expectation and probability given information set $\Omega_{t-1}$ as $E_{t-1}(\cdot)$ and $P_{t-1}(\cdot)$ respectively, we may define

$$
p_{t}=E_{t-1}\left(y_{t}\right)=P_{t-1}\left(y_{t}=1\right) .
$$

Moreover, to specify the conditional probability of positive excess stock returns $p_{t}$, we form a probit model

$$
p_{t}=\Phi\left(\pi_{t}\right)
$$

where $\Phi(\cdot)$ is the cumulative distribution function of the standard normal distribution and $\pi_{t}$ is a linear function of the variables in $\Omega_{t-1}$. Assuming a logistic distribution instead would yield a logit model.

To complete the model, the basic and most commonly used specification is the static probit model, where $\pi_{t}$ is specified as

$$
\pi_{t}=\omega+x_{t-1}^{\prime} \beta
$$

where $x_{t-1}$ includes lagged values of the explanatory variables and $\omega$ is a constant term. The static model (6) may also be extended in various ways. One option is to include lagged values of $y_{t}$, producing a dynamic probit model

$$
\pi_{t}=\omega+\delta_{1} y_{t-1}+x_{t-1}^{\prime} \beta
$$

It is important to note that in this paper, we restrict ourselves to the first-order case presented in model (7), as preliminary findings suggest that higher-order lags of $y_{t}$ do not add predictive power.

Alternatively, lagged values of the linear function $\pi_{t}$ may be added into the model to introduce an autoregressive structure. Augmenting the model by first-order lags of $\pi_{t}$, we get a first-order autoregressive probit model

$$
\pi_{t}=\omega+\alpha_{1} \pi_{t-1}+x_{t-1}^{\prime} \beta
$$

Finally, including the lagged values of both $y_{t}$ and $\pi_{t}$ yields a dynamic autoregressive probit model

$$
\pi_{t}=\omega+\alpha_{1} \pi_{t-1}+\delta_{1} y_{t-1}+x_{t-1}^{\prime} \beta
$$

The parameters of models (6)-(9) can be estimated using maximum likelihood (ML) methods. For more details on the estimation and the calculation of Newey-West type robust standard errors, we refer to Kauppi and Saikkonen (2008). In this paper, we will employ all of the aforementioned models (6)-(9), in order to study whether the dynamic (7), autoregressive (8), and dynamic autoregressive (9) extensions to the standard probit model (6) are useful in the context of predicting the direction of the excess stock market return. 


\subsection{Goodness-of-fit Measures and Statistical Tests}

As we employ different types of models, i.e. binary and continuous dependent variable models, in both in-sample estimation and out-of-sample forecasting, we need a number of different measures to evaluate the statistical fit and predictability of our models. For the predictive regressions like (1), we evaluate the in-sample fit by the commonly used adjusted- $R^{2}$ measure. For the dynamic probit models, we employ similar goodness-of-fit measures as Nyberg (2011). The main measure used to evaluate the in-sample goodness-of-fit of the probit models is the adjusted pseudo- $R^{2}$ measure of Estrella (1998), defined as

$$
\text { adj.ps } R^{2}=1-\left(\log L_{u}-\log L_{c}\right)^{-(2 / T) \log L_{c}} \times(T-1) /(T-k-1),
$$

where $\log L_{u}$ and $\log L_{c}$ are the maximum values of the estimated constrained and unconstrained loglikelihood functions respectively, $T$ is the length of the sample, and $k$ is the number of explanatory variables. We use the adjusted form of the measure since it takes into account the trade-off between improvement in model fit and the loss in degrees of freedom. It is worth noting that, although it is on a similar scale as the adjusted- $R^{2}$ generated in ordinary least squares (OLS) regression, these two measures are not directly comparable. For the probit models we also report the Bayesian information criterion (BIC), which is typically used for model selection purposes.

Although in in-sample estimation we are interested in the statistical fit of the models, the main focus is on studying the statistical significance of the coefficients for industry portfolios. In out-of-sample forecasting in Section 6, we focus on the comparison of the sign forecasting performance of each model. In our application, the results produced by the probit models are probability forecasts of positive excess market returns in a given period. Therefore, we need to convert these probabilities into sign forecasts based on a threshold value. In other words, the sign forecast is defined as

$$
\hat{y}_{t}=\mathbf{1}\left[p_{t}>c\right]
$$

where $\mathbf{1}[\cdot]$ denotes an indicator function and $p_{t}$ is given in (4) and (5). In this study, we use a natural threshold of $c=0.50$, which is also the most commonly used one in the literature (see, e.g., Leung et al. (2000), Nyberg (2011) and Chevapatrakul (2013)). Similarly, we need to convert the results from predictive regressions into sign forecasts. This is done in the same way as for the realized excess market returns in (2). In other words, if $\hat{R E_{t}}$ in model (1) is positive, we get a signal forecast $\hat{y}_{t}=1$.

Based on the threshold and the obtained forecasting signals, we report the success ratio of our forecasts, denoted as SR. This ratio can be expressed as

$$
S R=\frac{\hat{y}^{u u}+\hat{y}^{d d}}{\hat{y}^{u u}+\hat{y}^{d u}+\hat{y}^{u d}+\hat{y}^{d d}},
$$

where the forecasts are classified as

$$
\begin{aligned}
& \hat{y}^{u u}=\sum_{t=1}^{T} \mathbf{1}\left[\hat{y}_{t}=1, y_{t}=1\right], \\
& \hat{y}^{u d}=\sum_{t=1}^{T} \mathbf{1}\left[\hat{y}_{t}=1, y_{t}=0\right], \\
& \hat{y}^{d u}=\sum_{t=1}^{T} \mathbf{1}\left[\hat{y}_{t}=0, y_{t}=1\right], \\
& \hat{y}^{d d}=\sum_{t=1}^{T} \mathbf{1}\left[\hat{y}_{t}=0, y_{t}=0\right],
\end{aligned}
$$

In these expressions $\hat{y}_{t}$ is the forecast of $y_{t}, u$ is an upward signal and $d$ is a downward signal.

Pesaran and Timmermann (1992) have proposed a statistical test of directional accuracy (DA) that measures whether the value of SR is significantly different from the success ratio that would be obtained when the realized values $y_{t}$ and the forecasts $\hat{y}_{t}$ are independent. A detailed description of the test statistic is also presented by Granger and Pesaran (2000), and following their notation, the test statistic can be written as

$$
D A=\frac{\sqrt{T}(H R-F R)}{\left(\frac{\hat{P}_{y}\left(1-\hat{P}_{y}\right)}{\bar{y}(1-\bar{y})}\right)^{1 / 2}}
$$


where $\bar{y}$ is the $T$-month sample average of the binary variable $y_{t}$, the hit rate $H R=\frac{\hat{y}^{u u}}{\hat{y}^{u u}+\hat{y}^{d u}}$, and false rate $F R=\frac{\hat{y}^{u d}}{\hat{y}^{u d}+\hat{y}^{d d}}$. Finally, $\hat{P}_{y}=\bar{z} H R+(1-\bar{z}) F R$. The test statistic (13) has the asymptotic standard normal distribution under the null hypothesis that $y_{t}$ and $\hat{y}_{t}$ are independently distributed.

As an extension of the test statistic (13), Pesaran and Timmermann (2009) have recently suggested a new test of predictability that is better suited for market timing when there is serial correlation in $y_{t}$ and the signal forecasts $\hat{y}_{t}$. This test statistic can be written as

$$
P T=(T-1)\left(S_{y y, w}^{-1} S_{y \hat{y}, w} S_{\hat{y} \hat{y}, w}^{-1} S_{\hat{y} y, w}\right) \sim \chi_{1}^{2},
$$

where

$$
\begin{gathered}
S_{y y, w}=(T-1)^{-1} Y^{\prime} M_{w} Y, \\
S_{\hat{y} \hat{y}, w}=(T-1)^{-1} \hat{Y}^{\prime} M_{w} \hat{Y}, \\
S_{\hat{y} y, w}=(T-1)^{-1} \hat{Y}^{\prime} M_{w} Y, \\
S_{y \hat{y}, w}=(T-1)^{-1} Y^{\prime} M_{w} \hat{Y}, \\
M_{w}=I_{T-1}-W\left(W^{\prime} W\right)^{-1} W^{\prime}, \\
W=\left(\tau_{T-1}, Y_{-1}, \hat{Y}_{-1}\right),
\end{gathered}
$$

and $Y=\left(y_{2}, \ldots y_{T}\right)^{\prime}, \hat{Y}=\left(\hat{y}_{2}, \ldots \hat{y}_{T}\right)^{\prime}, Y_{-1}=\left(y_{1}, \ldots y_{T-1}\right), \hat{Y}_{-1}=\left(\hat{y}_{1}, \ldots \hat{y}_{T-1}\right)$, and $\tau_{t}$ is a $(T-1) \times 1$ vector of ones. We follow the previous notation where $\hat{Y}$ is a vector of forecasts of the event time series $Y$. Both of Pesaran and Timmermann's $(1992,2009)$ tests are especially useful in assessing the out-of-sample performance of the models, but we also report them along with in-sample results.

\subsection{Trading strategies}

In applications focusing on excess returns, the market timing ability of models is commonly tested using trading strategies based on their out-of-sample forecasts. This is motivated by Leitch and Tanner (1991), who argue that models performing well according to statistical criteria might not be profitable in market timing. In our paper, we will consider simple trading strategies similar to those in Leung et al. (2000) and Nyberg (2011). This will allow direct comparison of trading returns between the conventional predictive regressions and the probit models. These returns may also be compared to ones obtained by using common benchmarks, such as the buy-and-hold trading strategy.

For our trading strategy, we assume that an investor decides a financial asset allocation at the beginning of each month. The choice of assets consists of stocks (risky asset) and the one-month T-bill rate (risk-free asset). The investment decision is based on the various forecasting models. If the directional forecast $\hat{y}_{t}=1$, the investor invests only in stocks. In our case this is the CRSP market portfolio, which we assume tradable through a hypothetical index fund. If the forecast model predicts a downward movement in stock markets $\hat{y}_{t}=0$, the investor allocates the whole portfolio to one-month T-bills. In the basic setup we assume zero transaction costs and no short-sales for the sake of simplicity, but we also perform robustness checks allowing for both of these additional features.

When studying the profitability of investment strategies, one should also take into account the riskiness of the portfolios. The Sharpe ratio $(1966,1994)$ is the most commonly used measure of risk adjusted return in finance. It is a convenient tool in ranking portfolio performance, but its numerical value is difficult to interpret. It describes the amount of excess return that the investor receives for the added volatility from holding a more risky asset. In this study, the ex-post Sharpe ratio is defined as

$$
S=\frac{\left(r_{p}-r_{f}\right)}{\sigma_{p}},
$$

where $r_{p}$ and $\sigma_{p}$ are the return and standard deviation of the investment portfolio, and $r_{f}$ is the risk-free return. 


\section{Data}

There has been abundant research on economic and financial variables that can be used as predictors for excess stock returns. In terms of data, we start off by using a similar set of variables as Hong et al. (2007). We also entertain alternative predictive variables based on previous studies, such as Goyal and Welch (2008), who consider a comprehensive set of other potential predictors.

The stock market data are monthly returns from the Center for Research in Security Prices (CRSP), available at Kenneth French's data library ${ }^{1}$. We use monthly data ranging from 1946M1 to 2012M12. The dataset for the US stock market return is the excess market return on the value-weighted market portfolio $R E_{t}$, which is defined as the difference between the market return $R M_{t}$ and the risk-free rate $R F_{t}$ (i.e. $R E_{t}=R M_{t}-R F_{t}$ ). The data for the industry portfolios include monthly excess returns on 34 valueweighted industry portfolios similar to Hong et al. (2007). The data for the Agriculture, Forestry, and Fishing (AGRIC) and Real Estate (REIT) industries are only available from 1965M01 and $1972 \mathrm{M} 01$ onwards, respectively. Models including these two portfolios are therefore estimated for a shorter sample. ${ }^{2}$

In addition to stock returns, we use data for selected market fundamentals obtained from the St. Louis Federal Reserve Economic Data (FRED) library ${ }^{3}$. We include the growth rate of the consumer price index (CPI) as well as the default spread (DSPR) defined as the difference between BAA- and AAA-rated bond yields. The market dividend yield (MDY) is obtained for the S\&P500 companies, and it is defined as the ratio of annual dividends to current prices. Finally, we include a measure of monthly market volatility (MVOL) calculated from daily data on the market returns, in the same way as in French, Schwert, and Stambaugh (1987). We also consider the term spread (TERM) and the change in the 3-month T-bill rate $(3 \mathrm{MTH})$, which have been found useful predictors of excess stock returns in previous studies (e.g. Fama and French, 1989). Table 1 provides the details of the 34 industries used in our study and includes the means and standard deviations of the monthly returns.

\section{In-sample Results}

In the in-sample estimations, we experiment with a number of different explanatory variables and model specifications. We restrict ourselves to using only the first lags of the industry returns and other explanatory variables, which is typical in this kind of predicting exercises (see, e.g., Nyberg (2011) and Chevapatrakul (2013). In order to keep the models relatively parsimonious, we follow Hong et al. (2007), and set the maximum number of explanatory variables at six. Due to the large number of different model specifications, we only report the most relevant results. ${ }^{4}$ Specifically, we will present results from models including the same explanatory variables as Hong et al. (2007); the lagged excess market return (RE), consumer price inflation (CPI), default spread (DSPR), market dividend yield (MDY), and market volatility (MVOL). In addition, we report the results of an alternative specification that yields the best in-sample fit among models with at most six explanatory variables. We also consider three different in-sample periods in order to study whether the results vary in time. We estimate models for each of the 34 industries separately.

Our full sample runs from 1946M1 to 2012M12. In order to compare our results with those of Hong et al. (2007), we also use a subsample that covers 1946M1-2002M12. Finally, as we will perform out-of-sample forecasting in Section 6, we will also study results for a shorter in-sample period running from 1946M11985M12. This selection allows us to have an adequately long out-of-sample period of 27 years. The use of different subsamples will allow us to study the time-variability in the explanatory power of the models in general as well as the potential changes in the coefficients of predictive variables.

\subsection{In-sample Results from Predictive Regressions}

We start by studying results of predictive regressions in the style of Hong et al. (2007). As discussed above, we use a similar set of predictive variables, but extend their sample size by ten years, i.e. until the end of 2012. By doing this we are able to study whether there has been substantial changes in the predictive power of industry returns on market returns over the last decade. Some differences in results could be expected since the latter part of the sample contains the recent financial crisis period. We report the results for the

\footnotetext{
1 http://mba.tuck.dartmouth.edu/pages/faculty/ken.french/index.html

${ }^{2}$ In Section 7 we also study the robustness of our findings using daily frequency data. This data is also obtained from the Kenneth French's data library.

3 http://research.stlouisfed.org/fred2/

4 All the other results are available upon request.
} 
predictive regressions including the industry METAL in Table 2 as an illustration of our findings, as it is among the industries with stronger predictive ability. The METAL portfolio is a natural choice in the sense that Hong et al. (2007) also use it to illustrate their results, and using it allows us to compare findings between the studies. The metal industry is also a particularly interesting case, because as a commodity industry it provides raw materials to other industries, thus having a direct linkage to other industries (see Menzly and Ozbas (2010)) and a possible channel through which the return on the METAL portfolio might affect returns in the broader market. By similar reasoning, some of the strongly procyclical industries might not include information that would consistently lead the market, so we should not necessarily expect to find strong results for all industries, especially since we include the lagged excess market return $\left(\mathrm{RE}_{t-1}\right)$ as one of the predictors. We do, however, also report the industry coefficients and adjusted- $R^{2}$ values for all of the 34 industries in the first column of Table 3.

\section{[Table 2 here]}

The findings in the first, third and fifth columns of Table 2 indicate that the default spread and market volatility have low predictive power. Thus, we also examine different specifications of the models with fewer explanatory variables and some alternative predictors. Previous studies have suggested that the term spread and short term interest rates are useful predictors of the excess stock market returns (see, e.g. Campbell and Thompson (2008)). As it turns out, we find the best overall fit measured by the adjusted- $R^{2}$ when we replace the default spread and the market volatility with the term spread (TS) and the first difference of the 3-month T-bill (3MTH) rate. As indicated in the second, fourth, and sixth columns of Table 2 for the model with the METAL portfolio, the in-sample fit of the model is improved rather significantly by this change. At the same time the statistical significance of the METAL-variable is reduced, as can be seen by comparing the first two columns. We also considered models with three and five predictors, but in general the six variable models produce the best fit.

Another key issue that can be seen in Table 2 is that the model fit in terms of the adjusted- $R^{2}$ is inferior for the longer samples. Compared to the shortest sample period used, the adjusted $R^{2}$ is almost double that of the full sample. This indicates that the predictability of excess stock market returns seems to vary substantially in time, which is an issue discussed in a number of papers, including Timmermann (2008).

\section{[Table 3 here]}

Since the alternative specification that includes TS and 3MTH as explanatory variables generally produces a higher in-sample fit, we focus on results of these models. As can be seen from the first column of Table 3, our results indicate that there are only three out of 34 industries, including Nonmetalic Minerals Except Fuels (STONE), Petroleum and Coal Products (PTRLM), and Finance, Insurance, and Real Estate (MONEY), that have statistically significant coefficients at the 5\% level. Compared to the 12 out of 34 industries found by Hong et al. (2007), this is a clear reduction. At the $10 \%$ significance level, there are a further two industries that show predictive power for the market return. These industries are PRINT and TV. Hence, in total we find only five industries that show some level of statistical significance, compared with 14 reported by Hong et al. (2007). Using the same explanatory variables as the original specification in Hong et al. (2007), the number of statistically significant industry coefficients (at least at the $10 \%$ level) increases to $8 .{ }^{5}$ This implies that the lagged term structure (TS) and lagged three-month T-bill rate (3MTH) capture some of the same information as the industry portfolios, and reduces their statistical significance. This finding applies throughout the results of our study, but the model fits measured by the adjusted- $R^{2}$ would be considerably lower if these control variables were left out.

Time-variation in the predictive relations is one potential explanation to the differences in results between our study and that of Hong et al. (2007). It is also worth noting that there have been some changes in the composition of the industry portfolios in Kenneth French's database, which may have lead to changes in the results. For these reasons, we also replicate the predictive regressions using the same sample (1946M12002M12) as Hong et al. (2007). Our findings are somewhat different from theirs, as we find that using the currently available datasets and our alternative specification (including TS and 3MTH), the returns on only two industry portfolios show statistically significant predictive ability for the excess market return at the $5 \%$ level and further four at the $10 \%$ level. $^{6}$ It is noteworthy that the results based on the exact same predictors as Hong et al. (2007) are stronger in terms of statistical significance of industry coefficients, which indicates that the main differences in results arises from the use of different control variables.

In Section 6, we will consider out-of-sample forecasts for the period 1986M1-2012M12. Therefore, we

\footnotetext{
5 Hong et. al (2007) have revised their results to cover the period 1946-2013 in a recent note (2014), available on Rossen Valkanov's website: http://rady.ucsd.edu/docs/faculty/valkanov/Note_10282014.pdf?pdf=Note_10282014. They also report that with a longer sample, fewer industries seem to lead the stock market.

6 These findings are available upon request.
} 
have also studied findings for the in-sample period of 1946M1-1985M12. These findings are not presented in the form of a table for all industries, but they indicate that excess returns of three industries have predictive ability for the excess market return at the $5 \%$ level and a further three at the $10 \%$ level. In general, the results for the predictive regressions do not change much in different samples in terms of which industry portfolios have predictive power, although this is the case for METAL in Table 2.

\subsection{In-sample Results From Dynamic Probit models}

In the previous section, we studied predictive regressions, where the dependent variable was the U.S. excess stock market return. In this section we employ the static (6) and dynamic probit models (7)-(9), where the dependent variable is the directional component of the return, as defined in equation (2). For the static probit model (6) for the full sample 1946M1-2012M12, the results in Table 3 indicate that two (of the 34) industry coefficients show statistically significant predictive power at the $5 \%$ level. These industries are INSTR and TV. Further four industries show statistical significance at the 10\% level; METAL, CNSTR, PRINT, and MONEY. All except INSTR are among the same industries that also Hong et al. (2007) reported to have predictive power. However, in general, our results do appear to be somewhat weaker in the sense that we find less evidence on the explanatory power of industry returns. We report the results for the static probit models including the industry METAL in Table 4. As in the case of the predictive regressions, the model that includes TS and 3MTH has a better in-sample fit than the model including DSPR and MVOL, measured in this case with the adjusted pseudo- $R^{2}$. For this reason, we focus mainly on the results of this specification, although evidence for the explanatory power of industry portfolio returns would be slightly stronger if we would use the same set of explanatory variables as Hong et al. (2007). It should also be pointed out that for the sample period 1946M1-1985M12 only two of the 32 industry coefficients are statistically significant, so the sample period does have an impact on these results. ${ }^{7}$ Differences in results between sample periods can also be seen in Table 4 in the case of the model with the METAL portfolio.

\section{[Table 4 here]}

The signs of the statistically significant industry coefficients in the static probit models are similar to those obtained using predictive regressions. These signs can also be given economic interpretations. It is noteworthy that, e.g., the returns in the METAL industry portrays the commodity prices of metal, which are typically countercyclical. Since the relationship between business cycles and stock markets is typically positive, the estimated negative sign makes economic sense. Industries that are not related to other economic fundamentals are likely contain information that is not captured by other predictors. On the other hand, industries such as PRINT and MONEY are commonly thought of as being procyclical, which is also in line with their obtained coefficients. In terms of the hypothesis of gradual diffusion across markets, one could expect that the industries that receive the least investor attention are likely to contain information that diffuses gradually across markets, but testing specifically for this is out of the scope of our study. A similar idea has, however, been tested by Rizova (2013), who studies the gradual diffusion of information in the context of international trade flows.

The in-sample estimation results of the dynamic probit models are rather interesting. Table 5 contains results obtained with the model including the METAL portfolio as an explanatory variable, while in Table 3 we report the results for the remaining industries. The results of the so-called dynamic specification (7) are almost identical to those of the static probit model (6). The reason for this is most likely that we already have the lagged excess market return $R E_{t-1}$ in the set of control variables, so the lagged sign of the excess market return $y_{t-1}$ turns out to be statistically insignificant. We also entertained models that excluded $R E_{t-1}$, but the overall in-sample fit was considerably lower.

\section{[Table 5 here]}

The results from autoregressive probit models (8) indicate that none of the coefficients for the industry returns are any longer statistically significant when we include the first lag of $\pi_{t}$ in the model. However, the coefficients of the lagged pi's are, in general, highly statistically significant, and the pseudo- $R^{2}$ values do increase substantially compared with the static (6) and dynamic (7) specifications. The results of the dynamic autoregressive probit models (9) are rather similar to those of the autoregressive probit models. In general, the adjusted pseudo- $R^{2}$ values are rather low, generally varying between $1.5 \%$ and $4 \%$. Overall, low explanatory power is typical in models for predicting stock returns. For instance, Rapach and Zhou (2013)

\footnotetext{
7 Findings available by request.
} 
mention that an upper bound for the predictability of stock returns (using $R^{2}$ ) could be evaluated to be around $8 \%$, which is still too loose to be binding in empirical applications.

Overall, our in-sample results indicate that returns from only a few industry portfolios are useful predictors of the excess market returns. However, the results of the $D A$ and $P T$ tests suggest that the signs of the excess market returns are predictable. The findings presented in Tables 3 and 4 indicate that we reject the null of no predictability in each of the specifications (including the METAL portfolio).

A natural comparison for our results are the findings of Nyberg (2011), who also studies the directional predictability of the excess return on the US stock market. I contrast to our study, he considers the use of recession forecasts as predictors in dynamic probit models. In general, taking into account the different predictors and a different sample, our in-sample findings are rather similar to his. The pseudo- $\mathrm{R}^{2}$ measures are slightly lower in our study, but the results are not directly comparable since employ the adjusted pseudo- $\mathrm{R}^{2}$ and have a longer sample size. ${ }^{8}$ On the other hand, the success ratios in our study are higher than those of Nyberg (2011), showing that our models do actually perform rather well compared to his. It is also important to note that, the recession forecasts employed as predictors by Nyberg (2011) are based on an autoregressive probit model using the term spread and nominal stock returns as predictors, which are already being used as predictors in our models, so we are actually using the same information in a slightly different way.

Compared with Hong et al. (2007), we find less evidence in favor of the hypothesis that information diffuses slowly across markets. Goyal and Welch (2008) note that it is not uncommon in studies focusing on predicting the equity premium that following studies using similar variables have found weaker or contradictory results, and above we have discussed a number of potential reasons for this in this study. Although our results are not very strong in terms of the in-sample predictive ability of excess industry returns, we have found interesting results on the differences between predictive regressions and dynamic probit models. In the next section we make out-of-sample forecasts comparing the models presented above, paying attention especially on the industries that had statistically significant in-sample predictive power.

\section{Out-of-sample results}

In this study, the out-of-sample period runs from 1986M1 to 2012M12, including 324 observations. We make one-month-ahead sign forecasts of the of excess stock market returns. We employ an expanding (recursive) estimation window when constructing the out-of-sample forecasts. Our in-sample results indicated that the predictive power of the models has changed in the last 27 years, so the choice of the out-of-sample period may have an effect on the results. The issue of splitting the data into estimation and evaluation periods is discussed e.g. by Hansen and Timmermann (2012), who demonstrate that out-of-sample forecast results may be highly dependent on the sample split, especially if the evaluation sample is left short. Therefore, to maximize the power of the forecast evaluation tests, we have selected a rather long out-of-sample period.

The out-of-sample forecasting performance is analyzed using a number of different measures. We find that the out-of-sample pseudo- $R^{2}$ measures are in many cases negative for the static probit model, which is an implication of a relatively low level of predictability, commonly found in models for excess stock returns. This is an issue that has been discussed in a number of previous papers. It is not uncommon that forecasting results deemed statistically insignificant by 'traditional' statistical measures are still economically significant (see e.g. Cenesizoglu and Timmermann, 2012). Therefore, we employ a number measures, such as the success ratio (SR) and both of the Pesaran and Timmermann $(1992,2009)$ tests to evaluate the out-of-sample performance of our models.

Again, we illustrate our findings using the model with the METAL portfolio included as an explanatory variable. These results are reported in Table 6 . The results indicate that the best out-of-sample performance among the probit models is obtained with the dynamic (7) version of the model, with $64.5 \%$ correct forecasts. The static probit model (6) produces rather similar results $(64.2 \%)$, but the autoregressive (8) and especially the dynamic autoregressive (9) model perform worse, with $61.7 \%$ and $59.9 \%$ forecast accuracies, respectively. This shows that good in-sample fit does not necessarily imply good performance out-of-sample, as the autoregressive probit model was superior to the static and dynamic models evaluated by the in-sample adjusted pseudo- $R^{2}$. The predictive power of the static and dynamic probit models is also statistically significant even at the $1 \%$ level according to the two forms of the Pesaran and Timmermann test in equations (13) and (14). Finally, it is noteworthy that the success ratio obtained for the predictive regression model is $58.6 \%$, which is lower than for any of the probit models (see the first column in Table 6). One potential

8 The adjusted pseudo- $\mathrm{R}^{2}$ receives values that are lower than those of the unadjusted measure, since it includes a term that penalizes for each extra predictor included. 
reason for the inferior performance is that predictive regression models have not been specifically designed for directional forecasting.

\section{[Table 6 here]}

The last two columns in Table 6 contains the results for the trading strategies based on forecasts of the corresponding models. As mentioned above, including trading strategies allows us to compare findings using both statistical and economic measures of forecast accuracy. We report the annual returns on each trading strategy, and in order to take into account the level of risk associated, we also report the Sharpe ratio (15). Results are generally in line with the findings based on the success ratio and the DA and PT test statistics. We find that the annual return for the buy-and-hold strategy is $9.75 \%$ for the period 1986M1-2012M12. The return based on the directional forecasts from the predictive regression model including the METAL portfolio is actually slightly lower than this $(9.65 \%)$. On the other hand, the return from the strategy based on the static probit model is $12.29 \%$, which is clearly higher than either of the above. In comparison, a static probit model excluding the industry return yields an annual return of $11.60 \%$. Furthermore, the return from the dynamic probit model including the METAL portfolio yields the highest investment return $(12.62 \%)$, whereas the returns from the autoregressive (10.63\%) and the dynamic autoregressive probit $(10.13 \%)$ models are slightly lower than those from the static model. The risk-adjusted returns measured by the Sharpe ratio rank the strategies in the same order as the unadjusted returns, as the standard deviations of the returns from the trading strategies are rather similar to one another.

We also consider a trading strategy where we include trading costs of $0.5 \%$. This cost is charged each time the contents of the investment portfolio is switched from stocks to the risk-free rate, and vice versa. Including transaction costs reduces the returns from the trading strategies, but does not change the findings significantly. The returns from the dynamic (7) and static probit (6) models remain considerably higher than the return from the buy-and-hold strategy. We also consider the use of short sales instead of using the risk-free rate as the alternative investment. This amplifies the differences between the trading strategies, but does not change the general findings. These results are available upon request.

The results for the models with the different industry portfolios are available in Table 7 . The findings are generally rather similar to those for the model with the METAL portfolio in Table 6 . The static probit model is most commonly the best among the probit models according to the SR measure. In three out of 34 cases the static models get a value of the PT test statistic (14) that is statistically significant at least at the $5 \%$ level and in further eight cases at the $10 \%$ level. The dynamic probit models perform considerably worse although they outperform the predictive regressions.

\section{[Table 7 here]}

The results in Tables 6 and 7 may also be compared to results from models that do not include industry portfolios as predictors. With the static probit model this specification produces a success ratio of $62.3 \%$, which is somewhat lower than that of the model with the METAL portfolio in Table 6 (64,2\%), but higher than those of the majority of other industries reported in Table 7. Overall, eight out of 34 industry portfolio augmented static probit models outperform the corresponding model with no industry portfolios included.

Finally, we study the returns on the investment strategies using a number of industries as well a specification in which no industries are included. We select the industries based on the performance measured by the success ratio (12), and these results are available in Table 8 . The findings indicate that the static probit model is generally the best predictive model also in terms of investment performance. The investment strategy based on the static probit including the construction (CNSTR) industry yields both the best annual return and the highest Sharpe ratio, as could be expected based on the results from the success ratio and PT statistics in Table 7.

\section{[Table 8 here]}

The dynamic probit models (in Table 8) do not perform quite as well as in the case of the model including the METAL portfolio return in Table 6, but they still outperform the autoregressive, dynamic autoregressive, and level models in terms of trading returns. In most cases the models including the return on either the CNSTR or WOOD industry outperform the models with no industry returns included (NOIND). Results for the models with the PTRLM industry return are more mixed.

Overall, we can conclude that as far as trading strategies are concerned, relying on the static probit model is generally the best option. Some industries, such as METAL and CNSTR do seem to contain information that can help gain higher returns in the out-of-sample period. This suggests that we should put a great emphasis on model selection when choosing the optimal industry portfolio as a predictor of the future sign of the excess market return. Our results for economic and statistical measures of forecast accuracy are also similar to one another. 
Finally, it is also interesting to compare the out-of-sample forecast results with findings from previous literature. Our results are generally in line with those obtained by Nyberg (2011), who also applies dynamic probit models in predicting stock market movements. Findings from both papers suggest that the static probit model (6) is an adequate model for predicting the direction of excess market returns, in terms of both statistical and economic goodness-of-fit measures. The success ratios and investment returns are generally higher in our out-of-sample exercise, but as the samples are different, the findings are not directly comparable.

\section{Experimenting with daily data}

As an extension to the main empirical models presented in Sections 5 and 6, we consider the use of daily data in our models. This allows us to study whether predictive information diffuses across markets more rapidly, i.e. to test the hypothesis of gradual diffusion of information across investors in the context of higher frequency data. This is particularly interesting, as the rate of the diffusion of information is likely to have changed in time and also varies depending on the type of information. On one hand, due to the very large number of observations associated with the daily data, and on the other hand, due to the potential change in speed of information diffusion, we limit ourselves to a shorter sample covering 1986-2012, which also corresponds with the out-of-sample period used for monthly data. Nevertheless, the total number of observations $(\mathrm{T}=6808)$ remains very high. As we consider the use of daily data mainly as a robustness check for the findings presented in the previous section, we only focus on in-sample findings.

Using daily data limits the number of potential predictors, because most macroeconomic variables are only available in monthly and lower frequencies. However, the stock market and industry portfolio returns are available in daily frequency at the Kenneth French's data library. From the same source, we also obtain daily data on the risk-free rate. Therefore, in our models using daily data, we employ the industry portfolios as predictors and control for effects from the lagged excess market return and the risk-free rate.

\section{[Table 9 here]}

Once again, following Hong et. al (2007), we illustrate our findings using the models that include the METAL industry portfolio as a predictor. These results are presented in Table 9, and they show that using daily data, the coefficient for the METAL portfolio is statistically significant in all four cases, providing further evidence that lagged return on the METAL portfolio contains useful predictive information for the excess market return. Overall, we find no notable differences between the four different model specifications, suggesting that the static probit is an adequate model in this application. However, it should be noted that the daily market returns are extremely noisy and therefore the overall level of predictability remains extremely low (adjusted pseudo- $\mathrm{R}^{2}$ varies between 0.0011 and 0.0013 ). This finding is further supported by the relatively low values of the success ratios and the statistically insignificant values of the DA and PT tests.

Overall, we find that nine out of 33 industry portfolios ${ }^{9}$ have a statistically significant coefficient (at least at the $10 \%$ level) for the static probit model using daily data, which confirms the finding that returns on lagged industry portfolios may contain useful predictive information for the direction of the excess market return.

\section{Conclusion and possible extensions}

The aim of this paper has been to study the predictive ability of industry portfolios for excess US stock market returns. We have employed conventional predictive regressions (1) and dynamic probit models (6)(9) to study the topic both in- and out-of-sample, and add to the literature by focusing on the directional component of the excess market returns. In our in-sample estimation, we find that a number of industries lead the stock markets by one month, the exact number depending varying between different model specifications used. However, contrary to previous findings by Hong et al. (2007), we find somewhat less evidence to support the gradual diffusion of information across markets, especially when we use the model specification that yields the highest in-sample fit. In addition to studying the predictive ability of industry portfolios, we also provide new results on the differences between in-sample estimation and out-of-sample forecasting. Our

\footnotetext{
9 Daily data for the industry REIT were not available, which reduced the number of industries to 33 . The nine industries with statistically significant coefficients included MINES, OIL, FOOD, APPRL, PTRLM, METAL, ELCTR, INSTR, and RTAIL. Findings for dynamic probit models (7)-(9) using daily data were similar to the ones obtained using the static probit models, as illustrated in Table 9 for the METAL portfolio.
} 
out-of-sample results indicate that the direction of excess market returns are predictable, and that certain industry portfolios do contain information that can be used for this purpose.

One of our key findings is that the dynamic probit models produce more accurate out-of-sample forecasts of the direction of the excess stock market returns than the conventional predictive regression model, which clearly supports the use of these models. Our findings also indicate that although the probit model including an autoregressive structure (8) yields the best in-sample fit, the more parsimonious static probit model (6) performs better out-of-sample. Our findings are substantiated by employing both statistical and economic measures of forecast accuracy, as they yield remarkably similar results in our application. This is an interesting result in itself because, for example, Cenesizoglu and Timmermann (2012) have suggested that the results from statistical tests and investment strategies are not always in line with each other.

In terms of profitability of trading strategies, we find that especially the metal and construction industry portfolios contain information that could be used to obtain higher investment returns during the out-ofsample period 1986M01-2012M12. Models including the excess returns of these two industry portfolios were also the best according to statistical criteria. How the information included in the industry portfolios would actually convert into exploitable arbitrage opportunities in the future is another issue.

As an extension of our main results obtained with models using monthly data, we have experimented with models employing daily data. It turns out that the results are robust to the change in data frequency, i.e. we still find that information in a number of industry portfolios are useful in predicting movements of the excess market return. The level of predictability in terms of model fit is lower in the models employing daily data, as one would expect based on the noise in daily returns.

This paper could be extended in a number of ways. One possibility is to use industry portfolio returns in excess of market returns as explanatory variables. A radically different approach would be the use of an indicator for bear and bull markets as the dependent variable instead of the direction of the monthly market movements, as is done by Nyberg (2013). The motivation for predicting these long periods of positive and negative returns is based on the idea that different types of investment opportunities are profitable during these regimes, and identifying the shifts from one regime to another is useful information for investors. Identifying turning points between bear and bull markets is closely related to the identification of business cycle turning points, for which the business cycle indicator of the National Bureau of Economic Research (NBER) is the most commonly used benchmark in the U.S., and it is used in most of the studies focusing on business cycles in real economic activity. For stock markets, no such clear benchmark exists, but, for example, mechanical dating rules can be devised to identify the turning points.

A number of other explanatory variables could also be considered. Especially the use of forward-looking variables, such as inflation expectations and consumer confidence indices, would be interesting, but the common problem with most of these is the limited sample length. In addition to studying whether industry portfolios lead the aggregate market, the models applied in this paper could potentially extended to facilitate the examination of interrelations between industry returns. These relations have previously been addressed in Kong et al. (2011) and Menzly and Ozbas (2010).

Acknowledgements Many thanks to Heikki Kauppi, Helinä Laakkonen, Markku Lanne, Matthijs Lof, Henri Nyberg, and participants of FDPE Econometrics Workshops I\&II 2013 (Helsinki, May and Dec 2013), the GSF and FDPE Winter Research Workshop in Finance (Turku, Nov 2013), and FindEcon'2014 (Lodz, May 2014) for useful comments. I also want to express my gratitude to the Finnish Foundation for Advancement of Securities Markets, the Yrjö Jahnsson foundation, and the Research Funds of the University of Helsinki for financial support.

\section{References}

1. Anatolyev S, Gospodinov N (2010) Modeling financial return dynamics via decomposition. J Bus Econ Stat 28:232-245

2. Campbell JY, Thompson SB (2008) Predicting excess returns out of sample: Can anything beat the historical average? Rev Financ Stud 21:1509-1531

3. Cenesizoglu T, Timmermann A (2012) Do return prediction models add economic value. J Bank Financ 36:2974-2987

4. Chevapatrakul T (2013) Return sign forecasts based on conditional risk: Evidence from the UK stock market index. J Bank Financ 37:2342-2353

5. Christoffesen PF, Diebold FX (2006) Financial asset returns, direction-of-change forecasting, and volatility dynamics. Manag Sci 52:1273-1287

6. Cole R, Moshirian F, Wu Q (2008) Bank stock returns and economic growth. J Bank Financ 32:995-1007 
7. Estrella A (1998) A new measure of fit for equations with dichotomous dependent variables. J Bus Econ Stat 16:198-205

8. Fama E, French K (1989) Business Conditions and expected returns on stocks and bonds. J Financ Econ 25:23-49

9. French K, Schwert GW, Stambaugh R (1987) Expected stock returns and volatility. J Financ Econ 19:3-29

10. Goyal A, Welch I (2008) A comprehensive look at the empirical performance of equity premium prediction. Rev Financ Stud 21:1455-1508

11. Granger CWJ, Pesaran MH (2000) Economic and statistical measures of forecast accuracy. J Forec 19:537-600

12. Hansen PR, Timmermann A (2012) Choice of sample split in out-of-sample forecast evaluation. European University Institute Working Paper ECO 2010/10

13. Hong H, Stein J (1999) A unified theory of underreaction, momentum trading, and overreaction in asset markets. J Financ 54:2143-2184

14. Hong H, Torous W, Valkanov R (2007) Do industries lead stock markets? J Financ Econ 83:367-396

15. Kauppi H, Saikkonen P (2008) Predicting U.S. recessions with dynamic binary response models. Rev Econ Stat 90:777-791

16. Kong A, Rapach D, Strauss J, Zhou G (2011) Predicting market components out of sample: asset allocation implications. J Portf Manag 37:29-41

17. Lamont O (2001) Economic tracking portfolios. J Econom 105:161-184

18. Leitch G, Tanner E (1991) Economic forecast evaluation: Profits versus conventional error measures. Am Econ Rev 81:580-590

19. Leung MT, Daouk H, Chen A-S (2000) Forecasting stock indices: a comparison of classification and level estimation models. Int J Forec 16:173-190

20. Menzly L, Ozbas O (2010) Market segmentation and cross-predictability of returns. J Financ 65:15551580

21. Merton R (1981) On Market Timing and Investment Performance: An Equilibrium Theory of Value for Market Forecasters. J Bus 54:363-406

22. Moskowitz T, Grinblatt M (1999) Do industries explain momentum? J Financ 54:1249-1290

23. Ng ECY (2012) Forecasting US recessions with various risk factors and dynamic probit models. J Macroecon 34:112-125

24. Nyberg H (2010) Dynamic probit models and financial variables in recession forecasting. J Forec 29:215230

25. Nyberg H (2011) Forecasting the direction of the US stock market with dynamic binary probit models. Int J Forec 27:561-578

26. Nyberg H (2013) Predicting bear and bull stock markets with dynamic binary time series models. J Bank Financ 37:3351-3363

27. Pesaran MH, Timmermann A (1992) A simple nonparametric test of predictive performance. J Bus Econ Stat 10:461-465

28. Pesaran MH, Timmermann A (2009) Testing dependence among serially correlated multi-category variables. J Am Stat Assoc 485:325-337

29. Rapach D, Zhou G (2013) Forecasting stock returns. In: Elliott, G, Timmermann A (eds), Handbook of Economic Forecasting, Volume 2A. Elsevier, Amsterdam, pp 328-383

30. Rizova S (2013) Trade momentum. J Int Finan Markets, Inst Money 24:258-293

31. Rydberg T, Shephard N (2003) Dynamics of trade-by-trade price movements: decomposition and models. J Financ Econom 1:2-25.

32. Sharpe WF (1966) Mutual fund performance. J Bus 39:119-138

33. Sharpe WF (1994) The Sharpe ratio. J Portf Manag 21:49-58

34. Timmermann A (2008) Elusive return predictability. Int J Forec 24:1-18 
Table 1 Summary statistics of industry portfolios and explanatory variables.

\begin{tabular}{|c|c|c|c|}
\hline Industry & Definition & Mean & St.Dev. \\
\hline AGRIC & Agriculture, Forestry, and Fishing & 0.499 & 7.987 \\
\hline MINES & Mining & 0.670 & 7.461 \\
\hline OIL & Oil and Gas Extraction & 0.809 & 7.095 \\
\hline STONE & Nonmetalic Minerals Except Fuels & 0.828 & 7.480 \\
\hline CNSTR & Construction & 0.672 & 7.114 \\
\hline FOOD & Food and Kindred Products & 0.678 & 4.149 \\
\hline SMOKE & Tobacco Products & 0.919 & 5.746 \\
\hline TXTLS & Textile Mill Products & 0.608 & 6.807 \\
\hline APPRL & Apparel and Other Textile Products & 0.509 & 6.624 \\
\hline WOOD & Lumber and Wood Products & 0.721 & 7.561 \\
\hline CHAIR & Furniture and Fixtures & 0.581 & 6.415 \\
\hline PAPER & Paper and Allied Products & 0.694 & 5.541 \\
\hline PRINT & Printing and Publishing & 0.545 & 5.562 \\
\hline CHEMS & Chemicals and Allied Products & 0.656 & 4.475 \\
\hline PTRLM & Petroleum and Coal Products & 0.824 & 5.047 \\
\hline RUBBR & Rubber and Miscellaneous Plastics Products & 0.736 & 5.983 \\
\hline LETHR & Leather and Leather Products & 0.759 & 6.734 \\
\hline GLASS & Stone, Clay, and Glass Products & 0.643 & 6.542 \\
\hline METAL & Primary Metal Industries & 0.502 & 7.002 \\
\hline MTLPR & Fabricated Metal Products & 0.674 & 5.164 \\
\hline MACHN & Machinery, Except Electrical & 0.708 & 6.153 \\
\hline ELCTR & Electrical and Electronic Equipment & 0.653 & 6.597 \\
\hline CARS & Transportation Equipment & 0.663 & 5.579 \\
\hline INSTR & Instruments and Related Products & 0.670 & 5.257 \\
\hline MANUF & Miscellaneous Manufacturing Industries & 0.631 & 6.455 \\
\hline TRANS & Transportation & 0.568 & 5.685 \\
\hline PHONE & Telephone and Telegraph Communication & 0.453 & 4.448 \\
\hline TV & Radio and Television Broadcasting & 0.897 & 6.604 \\
\hline UTILS & Electric, Gas, and Water Supply & 0.541 & 3.847 \\
\hline WHLSL & Wholesale & 0.621 & 5.465 \\
\hline RTAIL & Retail Stores & 0.663 & 5.031 \\
\hline MONEY & Finance, Insurance, and Real Estate & 0.633 & 5.200 \\
\hline SRVC & Services & 0.674 & 6.334 \\
\hline REIT & Real Estate Investment Trust & 0.480 & 5.170 \\
\hline $\mathrm{RE}$ & Excess Market Return & 0.581 & 4.319 \\
\hline MDY & Market Dividend Yield & 0.289 & 0.118 \\
\hline MVOL & Market Volatility & 4.016 & 2.193 \\
\hline DSPR & Default Spread & 0.073 & 0.033 \\
\hline CPI & Consumer Price Index & 0.317 & 0.457 \\
\hline $3 \mathrm{MTH}$ & 3-Month Treasury Bill & 0.350 & 0.241 \\
\hline TS & Term Spread & 0.130 & 0.108 \\
\hline
\end{tabular}

The table displays means and standard deviations of the variables used in the study. For the 34 industry portfolios, the variables are excess returns in excess of the one-month T-bill rate ranging from January 1946 to December 2012. The summary statistics for portfolio AGRIC are from July 1965 onwards and for portfolio REIT from January 1972 onwards. All variables are in monthly percentage points and at monthly frequency. 
Table 2 In-sample predictive regressions between the metal industry portfolio and the market portfolio.

\begin{tabular}{|c|c|c|c|c|c|c|}
\hline & 1946-2012 & 1946-2012 & 1946-2002 & 1946-2002 & 1946-1985 & 1946-1985 \\
\hline \multirow[t]{2}{*}{$C O N S T$} & -0.408 & -0.662 & -0.972 & -0.837 & $-1.849^{* *}$ & $-1.381^{* *}$ \\
\hline & $(0.609)$ & $(0.461)$ & $(0.632)$ & $(0.548)$ & $(0.712)$ & $(0.631)$ \\
\hline \multirow[t]{2}{*}{$M E T A L_{t-1}$} & $-0.077^{*}$ & -0.073 & $-0.104^{* *}$ & $-0.106^{* *}$ & $-0.120^{* *}$ & $-0.118^{* *}$ \\
\hline & $(0.046)$ & $(0.047)$ & $(0.040)$ & $(0.040)$ & $(0.055)$ & $(0.055)$ \\
\hline \multirow[t]{2}{*}{$R E_{t-1}$} & $0.159^{* *}$ & $0.143^{* *}$ & $0.151^{* *}$ & $0.133^{*}$ & $0.178^{* *}$ & 0.138 \\
\hline & $(0.068)$ & $(0.069)$ & $(0.070)$ & $(0.072)$ & $(0.090)$ & $(0.090)$ \\
\hline \multirow[t]{2}{*}{$I N F_{t-1}$} & $-0.977 * * *$ & $-0.871^{* *}$ & $-1.372^{* * *}$ & $-1.213^{* * *}$ & $-1.273^{* * *}$ & $-1.049 * * *$ \\
\hline & $(0.346)$ & $(0.339)$ & $(0.305)$ & $(0.305)$ & $(0.316)$ & $(0.325)$ \\
\hline \multirow[t]{2}{*}{$D S P R_{t-1}$} & 4.666 & & 6.784 & & 6.541 & \\
\hline & $(6.707)$ & & $(6.307)$ & & $(6.659)$ & \\
\hline \multirow{2}{*}{$M D Y_{t-1}$} & $3.487^{* * *}$ & $4.031^{* * *}$ & $4.504^{* * *}$ & $4.897 * * *$ & $5.680^{* * *}$ & $5.671^{* * *}$ \\
\hline & $(1.146)$ & $(1.190)$ & $(1.381)$ & $(1.434)$ & $(1.617)$ & $(1.620)$ \\
\hline \multirow[t]{2}{*}{$M V O L_{t-1}$} & -0.028 & & 0.022 & & 0.102 & \\
\hline & $(0.091)$ & & $(0.101)$ & & $(0.115)$ & \\
\hline \multirow[t]{2}{*}{$3 M T H_{t-1}$} & & $-0.902^{* * *}$ & & $-1.061^{* * *}$ & & $-0.969 * * *$ \\
\hline & & $(0.377)$ & & $(0.380)$ & & $(0.395)$ \\
\hline \multirow[t]{2}{*}{$T S_{t-1}$} & & 2.296 & & 2.293 & & $3.552^{*}$ \\
\hline & & $(1.450)$ & & (1.604) & & $(1.860)$ \\
\hline$R^{2}$ & 0.032 & 0.043 & 0.046 & 0.059 & 0.062 & 0.079 \\
\hline $\operatorname{adj} \cdot R^{2}$ & 0.025 & 0.035 & 0.038 & 0.051 & 0.050 & 0.067 \\
\hline $\mathrm{T}$ & 804 & 804 & 684 & 684 & 480 & 480 \\
\hline
\end{tabular}

The table presents in-sample results for predictive regressions (1) using three sample periods and two alternative specifications. The first specification (columns 1,3, and 5) is the one employed by Hong et al. (2007)and the second one (columns 2, 4, and 6) is the one proposed in this study. The table illustrates the in-sample predictive power of industry portfolio METAL and additional explanatory variables. Robust standard errors are in brackets. Notation *** corresponds with statistical significance at the $1 \%$ level, ${ }^{* *}$ at the $5 \%$ level, and ${ }^{*}$ at the $10 \%$ level. The predictive variables are discussed in Table 1. 
Table 3 The industry portfolios and their in-sample predictive power.

\begin{tabular}{|c|c|c|c|c|c|c|c|c|c|c|}
\hline \multirow{3}{*}{$\begin{array}{l}\text { IND. } \\
\text { MINES }\end{array}$} & \multicolumn{2}{|c|}{ LEVEL } & \multicolumn{2}{|c|}{ STATIC } & \multicolumn{2}{|c|}{ DYNAMIC } & \multicolumn{2}{|c|}{ AUTOREG. } & \multicolumn{2}{|c|}{ DYNAMIC AR. } \\
\hline & $I N D(-1)$ & $\operatorname{adj} . R^{2}$ & $I N D(-1)$ & $a d j . p s R^{2}$ & $I N D(-1)$ & $a d j . p s R^{2}$ & $I N D(-1)$ & $a d j . p s R^{2}$ & $I N D(-1)$ & $a d j . p s R^{2}$ \\
\hline & $\begin{array}{l}-0.035 \\
(0.031)\end{array}$ & 0.033 & $\begin{array}{l}-0.008 \\
(0.007)\end{array}$ & 0.029 & $\begin{array}{l}-0.008 \\
(0.007)\end{array}$ & 0.028 & $\begin{array}{l}-0.001 \\
(0.006)\end{array}$ & 0.034 & $\begin{array}{c}-0.001 \\
(0.006)\end{array}$ & 0.033 \\
\hline OIL & $\begin{array}{l}-0.037 \\
(0.031)\end{array}$ & 0.032 & $\begin{array}{l}-0.012 \\
(0.008)\end{array}$ & 0.030 & $\begin{array}{l}-0.012 \\
(0.008)\end{array}$ & 0.029 & $\begin{array}{l}-0.007 \\
(0.007)\end{array}$ & 0.036 & $\begin{array}{l}-0.007 \\
(0.007)\end{array}$ & 0.035 \\
\hline STONE & $\begin{array}{c}-0.053^{* *} \\
(0.024)\end{array}$ & 0.036 & $\begin{array}{c}-0.003 \\
(0.007)\end{array}$ & 0.028 & $\begin{array}{c}-0.003 \\
(0.007)\end{array}$ & 0.026 & $\begin{array}{c}0.001 \\
(0.006)\end{array}$ & 0.034 & $\begin{array}{c}0.001 \\
(0.008)\end{array}$ & 0.032 \\
\hline CNSTR & $\begin{array}{c}-0.049 \\
(0.032)\end{array}$ & 0.033 & $\begin{array}{c}-0.018^{*} \\
(0.011)\end{array}$ & 0.031 & $\begin{array}{c}-0.018^{*} \\
(0.011)\end{array}$ & 0.030 & $\begin{array}{l}-0.005 \\
(0.011)\end{array}$ & 0.035 & $\begin{array}{c}-0.008 \\
(0.076)\end{array}$ & 0.033 \\
\hline FOOD & $\begin{array}{l}-0.028 \\
(0.056)\end{array}$ & 0.031 & $\begin{array}{l}-0.023 \\
(0.015)\end{array}$ & 0.030 & $\begin{array}{l}-0.023 \\
(0.015)\end{array}$ & 0.029 & $\begin{array}{l}-0.011 \\
(0.019)\end{array}$ & 0.035 & $\begin{array}{l}-0.011 \\
(0.019)\end{array}$ & 0.034 \\
\hline SMOKE & $\begin{array}{l}-0.047 \\
(0.029)\end{array}$ & 0.033 & $\begin{array}{l}-0.007 \\
(0.008)\end{array}$ & 0.028 & $\begin{array}{c}-0.006 \\
(0.008)\end{array}$ & 0.027 & $\begin{array}{c}-0.005 \\
(0.008)\end{array}$ & 0.035 & $\begin{array}{l}-0.006 \\
(0.010)\end{array}$ & 0.033 \\
\hline TXTLS & $\begin{array}{c}0.008 \\
(0.030)\end{array}$ & 0.030 & $\begin{array}{r}-0.0008 \\
(0.008)\end{array}$ & 0.027 & $\begin{array}{c}3 \mathrm{e}-06 \\
(0.008)\end{array}$ & 0.026 & $\begin{array}{c}-0.004 \\
(0.007)\end{array}$ & 0.034 & $\begin{array}{c}-0.004 \\
(0.007)\end{array}$ & 0.033 \\
\hline APPRL & $\begin{array}{c}0.027 \\
(0.037)\end{array}$ & 0.031 & $\begin{array}{c}0.004 \\
(0.011)\end{array}$ & 0.027 & $\begin{array}{c}0.004 \\
(0.010)\end{array}$ & 0.026 & $\begin{array}{c}0.002 \\
(0.012)\end{array}$ & 0.034 & $\begin{array}{c}0.002 \\
(0.012)\end{array}$ & 0.033 \\
\hline WOOD & $\begin{array}{c}-0.015 \\
(0.028)\end{array}$ & 0.031 & $\begin{array}{c}0.001 \\
(0.009)\end{array}$ & 0.027 & $\begin{array}{c}0.001 \\
(0.009)\end{array}$ & 0.026 & $\begin{array}{c}0.006 \\
(0.006)\end{array}$ & 0.035 & $\begin{array}{c}0.006 \\
(0.006)\end{array}$ & 0.034 \\
\hline CHAIR & $\begin{array}{l}-0.005 \\
(0.039)\end{array}$ & 0.030 & $\begin{array}{c}-0.003 \\
(0.011)\end{array}$ & 0.027 & $\begin{array}{l}-0.003 \\
(0.011)\end{array}$ & 0.026 & $\begin{array}{c}-0.004 \\
(0.008)\end{array}$ & 0.034 & $\begin{array}{c}-0.004 \\
(0.008)\end{array}$ & 0.033 \\
\hline PAPER & $\begin{array}{c}-0.034 \\
(0.049)\end{array}$ & 0.031 & $\begin{array}{c}0.003 \\
(0.013)\end{array}$ & 0.027 & $\begin{array}{c}0.003 \\
(0.013)\end{array}$ & 0.026 & $\begin{array}{l}-0.007 \\
(0.010)\end{array}$ & 0.035 & $\begin{array}{c}-0.006 \\
(0.049)\end{array}$ & 0.033 \\
\hline PRINT & $\begin{array}{l}0.091^{*} \\
(0.047)\end{array}$ & 0.035 & $\begin{array}{l}0.022^{*} \\
(0.013)\end{array}$ & 0.030 & $\begin{array}{l}0.022^{*} \\
(0.013)\end{array}$ & 0.029 & $\begin{array}{c}0.019 \\
(0.017)\end{array}$ & 0.037 & $\begin{array}{c}0.020 \\
(0.016)\end{array}$ & 0.035 \\
\hline CHEMS & $\begin{array}{l}-0.006 \\
(0.065)\end{array}$ & 0.030 & $\begin{array}{c}0.006 \\
(0.019)\end{array}$ & 0.027 & $\begin{array}{c}0.006 \\
(0.019)\end{array}$ & 0.026 & $\begin{array}{c}0.010 \\
(0.016)\end{array}$ & 0.035 & $\begin{array}{c}0.010 \\
(0.016)\end{array}$ & 0.034 \\
\hline PTRLM & $\begin{array}{c}-0.090^{* *} \\
(0.040)\end{array}$ & 0.037 & $\begin{array}{l}-0.017 \\
(0.011)\end{array}$ & 0.030 & $\begin{array}{l}-0.017 \\
(0.011)\end{array}$ & 0.029 & $\begin{array}{c}-0.006 \\
(0.031)\end{array}$ & 0.034 & $\begin{array}{c}-0.009 \\
(0.064)\end{array}$ & 0.033 \\
\hline RUBBR & $\begin{array}{l}-0.019 \\
(0.041)\end{array}$ & 0.031 & $\begin{array}{c}0.001 \\
(0.013)\end{array}$ & 0.027 & $\begin{array}{c}0.001 \\
(0.013)\end{array}$ & 0.026 & $\begin{array}{c}-0.011 \\
(0.007)\end{array}$ & 0.036 & $\begin{array}{l}-0.011 \\
(0.007)\end{array}$ & 0.035 \\
\hline LETHR & $\begin{array}{c}0.021 \\
(0.030)\end{array}$ & 0.031 & $\begin{array}{l}-0.008 \\
(0.008)\end{array}$ & 0.028 & $\begin{array}{l}-0.008 \\
(0.008)\end{array}$ & 0.027 & $\begin{array}{l}-0.002 \\
(0.007)\end{array}$ & 0.034 & $\begin{array}{c}-0.002 \\
(0.007)\end{array}$ & 0.033 \\
\hline GLASS & $\begin{array}{c}-0.007 \\
(0.038)\end{array}$ & 0.030 & $\begin{array}{c}-0.006 \\
(0.011)\end{array}$ & 0.028 & $\begin{array}{l}-0.006 \\
(0.011)\end{array}$ & 0.027 & $\begin{array}{c}-0.012 \\
(0.007)\end{array}$ & 0.037 & $\begin{array}{c}-0.012 \\
(0.008)\end{array}$ & 0.035 \\
\hline METAL & $\begin{array}{c}-0.073 \\
(0.047)\end{array}$ & 0.035 & $\begin{array}{c}-0.022^{*} \\
(0.011)\end{array}$ & 0.032 & $\begin{array}{c}-0.022^{*} \\
(0.011)\end{array}$ & 0.031 & $\begin{array}{c}-0.009 \\
(0.011)\end{array}$ & 0.036 & $\begin{array}{c}-0.011 \\
(0.103)\end{array}$ & 0.034 \\
\hline MTLPR & $\begin{array}{l}-0.002 \\
(0.059)\end{array}$ & 0.030 & $\begin{array}{l}-0.016 \\
(0.016)\end{array}$ & 0.028 & $\begin{array}{l}-0.015 \\
(0.016)\end{array}$ & 0.027 & $\begin{array}{l}-0.013 \\
(0.011)\end{array}$ & 0.036 & $\begin{array}{c}-0.013 \\
(0.010)\end{array}$ & 0.034 \\
\hline MACHN & $\begin{array}{c}0.045 \\
(0.048)\end{array}$ & 0.031 & $\begin{array}{c}0.014 \\
(0.013)\end{array}$ & 0.029 & $\begin{array}{c}0.014 \\
(0.013)\end{array}$ & 0.027 & $\begin{array}{c}0.007 \\
(0.013)\end{array}$ & 0.035 & $\begin{array}{c}0.007 \\
(0.013)\end{array}$ & 0.033 \\
\hline ELCTR & $\begin{array}{c}0.018 \\
(0.046)\end{array}$ & 0.031 & $\begin{array}{c}0.003 \\
(0.013)\end{array}$ & 0.027 & $\begin{array}{c}0.003 \\
(0.012)\end{array}$ & 0.026 & $\begin{array}{c}-0.008 \\
(0.008)\end{array}$ & 0.035 & $\begin{array}{c}-0.008 \\
(0.008)\end{array}$ & 0.034 \\
\hline CARS & $\begin{array}{l}-0.057 \\
(0.054)\end{array}$ & 0.032 & $\begin{array}{l}-0.017 \\
(0.014)\end{array}$ & 0.029 & $\begin{array}{l}-0.017 \\
(0.014)\end{array}$ & 0.028 & $\begin{array}{c}-0.023 * * * \\
(0.008)\end{array}$ & 0.041 & $\begin{array}{c}-0.023 * * * \\
(0.008)\end{array}$ & 0.040 \\
\hline INSTR & $\begin{array}{c}0.045 \\
(0.052)\end{array}$ & 0.031 & $\begin{array}{c}0.035^{* *} \\
(0.016)\end{array}$ & 0.033 & $\begin{array}{c}0.035 * * \\
(0.016)\end{array}$ & 0.032 & $\begin{array}{c}0.033 \\
(0.050)\end{array}$ & 0.035 & $\begin{array}{c}0.024 \\
(0.014)\end{array}$ & 0.034 \\
\hline MANUF & $\begin{array}{l}-0.009 \\
(0.034)\end{array}$ & 0.030 & $\begin{array}{l}-0.009 \\
(0.009)\end{array}$ & 0.028 & $\begin{array}{l}-0.009 \\
(0.009)\end{array}$ & 0.027 & $\begin{array}{c}-0.004 \\
(0.007)\end{array}$ & 0.034 & $\begin{array}{l}-0.004 \\
(0.007)\end{array}$ & 0.033 \\
\hline TRANS & $\begin{array}{c}-0.034 \\
(0.043)\end{array}$ & 0.030 & $\begin{array}{l}-0.002 \\
(0.013)\end{array}$ & 0.027 & $\begin{array}{c}-0.002 \\
(0.013)\end{array}$ & 0.026 & $\begin{array}{c}-0.010 \\
(0.009)\end{array}$ & 0.036 & $\begin{array}{c}-0.010 \\
(0.009)\end{array}$ & 0.034 \\
\hline PHONE & $\begin{array}{l}-0.003 \\
(0.045)\end{array}$ & 0.030 & $\begin{array}{c}0.011 \\
(0.012)\end{array}$ & 0.028 & $\begin{array}{c}0.011 \\
(0.012)\end{array}$ & 0.027 & $\begin{array}{c}0.013 \\
(0.009)\end{array}$ & 0.037 & $\begin{array}{c}0.013 \\
(0.009)\end{array}$ & 0.036 \\
\hline $\mathrm{TV}$ & $\begin{array}{l}0.058^{*} \\
(0.031)\end{array}$ & 0.034 & $\begin{array}{c}0.021^{* *} \\
(0.010)\end{array}$ & 0.032 & $\begin{array}{c}0.020^{* *} \\
(0.010)\end{array}$ & 0.031 & $\begin{array}{c}0.011 \\
(0.035)\end{array}$ & 0.036 & $\begin{array}{c}0.013 \\
(0.032)\end{array}$ & 0.035 \\
\hline UTILS & $\begin{array}{c}0.024 \\
(0.061)\end{array}$ & 0.031 & $\begin{array}{l}-0.010 \\
(0.014)\end{array}$ & 0.028 & $\begin{array}{c}-0.010 \\
(0.014)\end{array}$ & 0.027 & $\begin{array}{c}0.004 \\
(0.011)\end{array}$ & 0.034 & $\begin{array}{c}0.004 \\
(0.011)\end{array}$ & 0.033 \\
\hline WHLSL & $\begin{array}{l}0.0002 \\
(0.050)\end{array}$ & 0.030 & $\begin{array}{l}-0.002 \\
(0.015)\end{array}$ & 0.027 & $\begin{array}{l}-0.002 \\
(0.015)\end{array}$ & 0.026 & $\begin{array}{c}-0.007 \\
(0.010)\end{array}$ & 0.035 & $\begin{array}{l}-0.007 \\
(0.010)\end{array}$ & 0.033 \\
\hline RTAIL & $\begin{array}{c}0.061 \\
(0.059)\end{array}$ & 0.032 & $\begin{array}{c}0.0002 \\
(0.016)\end{array}$ & 0.027 & $\begin{array}{c}-0.0005 \\
(0.016)\end{array}$ & 0.026 & $\begin{array}{l}-0.008 \\
(0.011)\end{array}$ & 0.035 & $\begin{array}{l}-0.008 \\
(0.011)\end{array}$ & 0.033 \\
\hline MONEY & $\begin{array}{c}0.131 * * \\
(0.066)\end{array}$ & 0.036 & $\begin{array}{l}0.029^{*} \\
(0.017)\end{array}$ & 0.030 & $\begin{array}{l}0.029^{*} \\
(0.017)\end{array}$ & 0.029 & $\begin{array}{c}0.013 \\
(0.031)\end{array}$ & 0.035 & $\begin{array}{c}0.017 \\
(0.048)\end{array}$ & 0.034 \\
\hline SRVC & $\begin{array}{c}0.061 \\
(0.049)\end{array}$ & 0.032 & $\begin{array}{c}0.009 \\
(0.014)\end{array}$ & 0.028 & $\begin{array}{c}0.008 \\
(0.014)\end{array}$ & 0.027 & $\begin{array}{c}0.008 \\
(0.008)\end{array}$ & 0.035 & $\begin{array}{c}0.008 \\
(0.008)\end{array}$ & 0.034 \\
\hline AGRIC & $\begin{array}{c}0.068 \\
(0.059)\end{array}$ & 0.018 & $\begin{array}{c}0.005 \\
(0.013)\end{array}$ & 0.018 & $\begin{array}{c}0.006 \\
(0.013)\end{array}$ & 0.016 & $\begin{array}{c}0.007 \\
(0.029)\end{array}$ & 0.018 & $\begin{array}{c}0.006 \\
(0.014)\end{array}$ & 0.016 \\
\hline REIT & $\begin{array}{c}0.017 \\
(0.038)\end{array}$ & 0.016 & $\begin{array}{c}0.003 \\
(0.010)\end{array}$ & 0.018 & $\begin{array}{c}0.003 \\
(0.010)\end{array}$ & 0.016 & $\begin{array}{c}0.001 \\
(0.011)\end{array}$ & 0.017 & $\begin{array}{c}0.001 \\
(0.010)\end{array}$ & 0.015 \\
\hline NOIND & & 0.028 & & 0.029 & & 0.027 & & 0.035 & & 0.034 \\
\hline
\end{tabular}

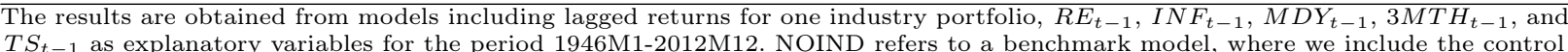
variables but no industry portfolios as predictors. For industries AGRIC and REIT the sample period is 1972M1-2012M12. Model LEVEL refers to a predictive regression model (1) and STATIC to a standard probit model (6), whereas DYNAMIC, AUTOREG., and DYNAMIC AR. refer to the dynamic (7), autoregressive (8), and dynamic autoregressive (9) probit models, respectively. Robust standard errors are in brackets, *** corresponds with significance at the $1 \%$ level, ${ }^{* *}$ at the $5 \%$ level, and $*$ at the $10 \%$ level. 
Table 4 In-sample static probit models with the metal industry portfolio.

\begin{tabular}{|c|c|c|c|c|c|c|}
\hline & 1946-2012 & 1946-2012 & 1946-2002 & 1946-2002 & 1946-1985 & $1946-1985$ \\
\hline \multirow[t]{2}{*}{ CONST } & 0.164 & 0.088 & 0.001 & 0.017 & -0.291 & -0.162 \\
\hline & $(0.180)$ & $(0.145)$ & $(0.210)$ & $(0.163)$ & $(0.038)$ & $(0.231)$ \\
\hline \multirow[t]{2}{*}{$M E T A L_{t-1}$} & $-0.022^{* *}$ & $-0.022^{*}$ & $-0.025^{*}$ & $-0.025^{*}$ & -0.025 & -0.025 \\
\hline & $(0.011)$ & $(0.011)$ & $(0.013)$ & $(0.013)$ & $(0.018)$ & $(0.018)$ \\
\hline \multirow[t]{2}{*}{$R E_{t-1}$} & $0.044^{* *}$ & $0.040^{* *}$ & $0.038^{* *}$ & $0.031^{*}$ & $0.051^{* *}$ & $0.042^{*}$ \\
\hline & $(0.017)$ & $(0.017)$ & $(0.019)$ & $(0.019)$ & $(0.026)$ & $(0.024)$ \\
\hline \multirow[t]{2}{*}{$I N F_{t-1}$} & $-0.433^{* * *}$ & $-0.406^{* * *}$ & $-0.495^{* * *}$ & $-0.457^{* * *}$ & $-0.474^{* * *}$ & $-0.431^{* * *}$ \\
\hline & $(0.110)$ & $(0.109)$ & $(0.121)$ & $(0.121)$ & $(0.128)$ & $(0.127)$ \\
\hline \multirow[t]{2}{*}{$D S P R_{t-1}$} & 0.160 & & -0.226 & & -0.042 & \\
\hline & $(1.772)$ & & $(2.056)$ & & $(2.180)$ & \\
\hline \multirow[t]{2}{*}{$M D Y_{t-1}$} & 0.637 & $0.725^{*}$ & $1.017^{* *}$ & $0.992^{* *}$ & $1.414^{* *}$ & $1.412^{* *}$ \\
\hline & $(0.402)$ & $(0.413)$ & $(0.466)$ & $(0.470)$ & $(0.642)$ & $(0.644)$ \\
\hline \multirow[t]{2}{*}{$M V O L_{t-1}$} & 0.0004 & & 0.020 & & 0.039 & \\
\hline & $(0.022)$ & & $(0.026)$ & & $(0.038)$ & \\
\hline \multirow[t]{2}{*}{$3 M T H_{t-1}$} & & $-0.190 * *$ & & $-0.227^{* *}$ & & $-0.223^{* *}$ \\
\hline & & $(0.094)$ & & $(0.097)$ & & $(0.110)$ \\
\hline \multirow[t]{2}{*}{$T S_{t-1}$} & & 0.447 & & 0.411 & & 0.069 \\
\hline & & $(0.442)$ & & $(0.493)$ & & $(0.670)$ \\
\hline$p s R^{2}$ & 0.033 & 0.038 & 0.032 & 0.037 & 0.031 & 0.034 \\
\hline adj.ps $R^{2}$ & 0.027 & 0.032 & 0.024 & 0.030 & 0.021 & 0.023 \\
\hline $\log -L$ & -529.323 & -527.204 & -450.294 & -448.198 & -314.392 & -313.318 \\
\hline$B I C$ & 552.732 & 550.613 & 473.137 & 471.041 & 335.993 & 334.919 \\
\hline$S R$ & 0.619 & 0.624 & 0.611 & 0.624 & 0.612 & 0.612 \\
\hline$D A$ & $4.307^{* * *}$ & $4.747^{* * *}$ & $3.662^{* * *}$ & $4.674^{* * *}$ & $3.749^{* * *}$ & $3.764^{* * *}$ \\
\hline$P T$ & $12.513^{* * *}$ & $14.080^{* * *}$ & $7.458^{* * *}$ & $13.573^{* * *}$ & $5.796^{* *}$ & $6.743^{* * *}$ \\
\hline
\end{tabular}

The table presents in-sample results for static probit models (6) including industry portfolio METAL as a explanatory variable. Robust standard errors in brackets, *** corresponds with significance at the $1 \%$ level, ${ }^{* *}$ at the $5 \%$ level, and $*$ at the $10 \%$ level. See also Notes to Table 2 . 
Table 5 In-sample results for dynamic probit models with the METAL industry portfolio 1946M1-2012M12.

\begin{tabular}{|c|c|c|c|c|}
\hline & STATIC & DYNAMIC & AUTOREG. & DYNAMIC AR. \\
\hline \multirow[t]{2}{*}{$C O N S T$} & 0.088 & 0.056 & 0.045 & 0.037 \\
\hline & $(0.145)$ & $(0.170)$ & $(0.086)$ & $(0.105)$ \\
\hline \multirow{2}{*}{$M E T A L_{t-1}$} & $-0.022^{*}$ & $-0.022^{*}$ & -0.009 & -0.009 \\
\hline & $(0.011)$ & $(0.011)$ & $(0.011)$ & $(0.011)$ \\
\hline \multirow{2}{*}{$R E_{t-1}$} & $0.040^{* *}$ & $0.035^{*}$ & 0.018 & 0.017 \\
\hline & $(0.017)$ & $(0.021)$ & $(0.017)$ & $(0.019)$ \\
\hline \multirow{2}{*}{$I N F_{t-1}$} & $-0.406^{* * *}$ & $-0.403^{* * *}$ & -0.206 & -0.207 \\
\hline & $(0.109)$ & $(0.108)$ & $(0.218)$ & $(0.226)$ \\
\hline \multirow{2}{*}{$M D Y_{t-1}$} & $0.725^{*}$ & $0.730^{*}$ & 0.290 & 0.294 \\
\hline & $(0.413)$ & $(0.411)$ & $(0.314)$ & $(0.330)$ \\
\hline \multirow[t]{2}{*}{$3 M T H_{t-1}$} & $-0.190^{* *}$ & $-0.191^{* *}$ & -0.108 & -0.121 \\
\hline & $(0.094)$ & $(0.094)$ & $(0.129)$ & $(0.141)$ \\
\hline \multirow{2}{*}{$T S_{t-1}$} & 0.447 & 0.449 & 0.058 & 0.060 \\
\hline & $(0.442)$ & $(0.440)$ & $(0.157)$ & $(0.162)$ \\
\hline \multirow[t]{2}{*}{$y_{t-1}$} & & 0.055 & & 0.014 \\
\hline & & $(0.154)$ & & $(0.121)$ \\
\hline \multirow[t]{2}{*}{$\pi_{t-1}$} & & & $0.684^{*}$ & 0.681 \\
\hline & & & $(0.402)$ & $(0.421)$ \\
\hline$a d j . p s R^{2}$ & 0.032 & 0.031 & 0.036 & 0.035 \\
\hline $\log -L$ & -527.20 & -527.13 & -525.31 & -525.30 \\
\hline$B I C$ & 550.61 & 553.89 & 552.06 & 555.40 \\
\hline$S R$ & 0.624 & 0.628 & 0.629 & 0.628 \\
\hline$D A$ & $4.747 * * *$ & $5.062^{* * *}$ & $5.164^{* * *}$ & $5.062^{* * *}$ \\
\hline$P T$ & $14.080 * * *$ & $17.179 * * *$ & $19.680 * * *$ & $15.248^{* * *}$ \\
\hline
\end{tabular}

The table reports in-sample results for binary response models used in the study, including the METAL industry portfolio as a predictive variable. The sample period is 1946M1-2012M12. Results for subsamples and alternative specifications are available upon request. See also Notes to Table 3.

Table 6 Out-of-sample results from predictive regressions and probit models with the METAL portfolio.

\begin{tabular}{lccccc}
\hline MODEL & SR & DA & PT & RETURN & SHARPE \\
\hline LEVEL & 0.586 & 1.546 & 1.549 & $9.65 \%$ & 1.51 \\
STATIC & 0.642 & $2.887^{* * *}$ & $7.576^{* * *}$ & $12.30 \%$ & 2.01 \\
DYNAMIC & 0.645 & $3.072^{* * *}$ & $9.955^{* * *}$ & $12.63 \%$ & 2.08 \\
AUTOREG. & 0.617 & $1.869^{*}$ & 2.674 & $10.63 \%$ & 1.63 \\
DYNAMIC AR. & 0.599 & 0.953 & 0.123 & $10.13 \%$ & 1.53 \\
\hline
\end{tabular}

The table presents statistical and economic measures used to study the out-of-sample performance of the employed models. Statistical measures include the success ratio (SR) and both of the Pesaran and Timmermann (1992,2009) statistics (DA) and (PT). Economic measures include annual returns in percentages and ex-post Sharpe ratios (15) for trading strategies based on forecasting models including the METAL industry portfolios. The out-of-sample period is 1986M1-2012M12. The results from the predictive regressions (1) are denoted as "level". See also Notes to Table 3. 
Table 7 Out-of-sample results for predictive regressions and probit models

\begin{tabular}{|c|c|c|c|c|c|c|c|c|c|c|}
\hline \multirow[t]{2}{*}{ INDUSTRY } & \multicolumn{2}{|c|}{ LEVEL } & \multicolumn{2}{|c|}{ STATIC } & \multicolumn{2}{|c|}{ DYNAMIC } & \multicolumn{2}{|c|}{ AUTOREG. } & \multicolumn{2}{|c|}{ DYNAMIC AR. } \\
\hline & SR & $\overline{\mathrm{PT}}$ & SR & $\overline{\mathrm{PT}}$ & SR & $\overline{\mathrm{PT}}$ & SR & $\overline{\mathrm{PT}}$ & SR & $\overline{\mathrm{PT}}$ \\
\hline MINES & 0.562 & 0.130 & 0.608 & 1.099 & 0.614 & 1.541 & 0.602 & 0.011 & 0.599 & 0.545 \\
\hline OIL & 0.574 & 1.563 & 0.614 & 1.297 & 0.608 & 0.651 & 0.617 & 2.629 & 0.614 & 1.988 \\
\hline STONE & 0.574 & 0.487 & 0.623 & 2.550 & 0.605 & 0.285 & 0.602 & 0.009 & 0.605 & 0.103 \\
\hline CNSTR & 0.556 & 0.124 & 0.648 & $9.421^{* * *}$ & 0.636 & $5.622^{* *}$ & 0.614 & 0.985 & 0.602 & 0.110 \\
\hline FOOD & 0.556 & 0.210 & 0.617 & 2.595 & 0.602 & 0.742 & 0.627 & $3.334^{*}$ & 0.605 & 0.002 \\
\hline SMOKE & 0.580 & $2.947^{*}$ & 0.623 & 2.689 & 0.614 & 0.634 & 0.611 & 0.051 & 0.608 & 0.040 \\
\hline TXTLS & 0.528 & 0.024 & 0.620 & 2.559 & 0.611 & 1.413 & 0.608 & 0.331 & 0.599 & 0.218 \\
\hline APPRL & 0.571 & 1.965 & 0.611 & 0.968 & 0.605 & 0.504 & 0.571 & 0.386 & 0.580 & 0.527 \\
\hline WOOD & 0.552 & 0.203 & 0.633 & $4.620 * *$ & 0.611 & 0.757 & 0.580 & 0.241 & 0.571 & 0.351 \\
\hline CHAIR & 0.549 & 0.121 & 0.620 & 1.487 & 0.620 & 2.324 & 0.611 & 0.001 & 0.602 & 0.019 \\
\hline PAPER & 0.571 & 0.520 & 0.620 & $2.939^{*}$ & 0.605 & 0.991 & 0.602 & 1.535 & 0.611 & 0.078 \\
\hline PRINT & 0.556 & 0.032 & 0.608 & 1.245 & 0.605 & 1.059 & 0.602 & 0.182 & 0.602 & 0.018 \\
\hline CHEMS & 0.562 & 0.480 & 0.630 & $3.432^{*}$ & 0.614 & 0.751 & 0.617 & 1.132 & 0.611 & 0.096 \\
\hline PTRLM & 0.549 & 0.013 & 0.623 & $3.682^{*}$ & 0.602 & 0.824 & 0.608 & 0.493 & 0.623 & 1.327 \\
\hline RUBBR & 0.568 & 0.678 & 0.620 & 1.728 & 0.614 & 1.442 & 0.596 & 0.871 & 0.611 & 1.257 \\
\hline LETHR & 0.552 & 0.005 & 0.614 & 1.400 & 0.614 & 1.531 & 0.586 & 0.259 & 0.586 & 0.228 \\
\hline GLASS & 0.531 & 0.278 & 0.627 & $3.540^{*}$ & 0.620 & 2.325 & 0.590 & 0.020 & 0.602 & 0.001 \\
\hline METAL & 0.586 & 1.548 & 0.642 & $7.576^{* * *}$ & 0.645 & $9.955 * * *$ & 0.617 & 2.674 & 0.599 & 0.124 \\
\hline MTLPR & 0.571 & 1.171 & 0.627 & $2.796^{*}$ & 0.611 & 1.081 & 0.593 & 0.560 & 0.599 & 0.121 \\
\hline MACHN & 0.580 & 1.387 & 0.586 & 0.237 & 0.586 & 0.104 & 0.602 & 0.594 & 0.586 & 0.037 \\
\hline ELCTR & 0.559 & 0.003 & 0.611 & 0.867 & 0.608 & 0.542 & 0.574 & 0.438 & 0.583 & 0.198 \\
\hline CARS & 0.565 & 0.212 & 0.627 & $3.157^{*}$ & 0.623 & 2.559 & 0.590 & 0.099 & 0.586 & 0.055 \\
\hline INSTR & 0.559 & 0.004 & 0.608 & 2.007 & 0.593 & 0.535 & 0.586 & 0.192 & 0.611 & 0.022 \\
\hline MANUF & 0.565 & 0.069 & 0.630 & $3.061^{*}$ & 0.617 & 1.302 & 0.590 & 0.330 & 0.596 & 0.015 \\
\hline TRANS & 0.565 & 0.480 & 0.617 & 1.381 & 0.605 & 0.524 & 0.602 & 0.862 & 0.599 & 0.159 \\
\hline PHONE & 0.562 & 0.001 & 0.605 & 0.222 & 0.599 & 0.006 & 0.593 & 0.244 & 0.617 & 1.073 \\
\hline TV & 0.571 & 0.940 & 0.605 & 0.094 & 0.593 & 0.001 & 0.620 & 0.968 & 0.605 & 0.060 \\
\hline UTILS & 0.556 & 0.205 & 0.605 & 0.744 & 0.605 & 0.843 & 0.605 & 0.038 & 0.605 & 0.003 \\
\hline WHLSL & 0.549 & 0.001 & 0.623 & 2.542 & 0.602 & 0.179 & 0.620 & 0.613 & 0.602 & 0.001 \\
\hline RTAIL & 0.565 & 0.405 & 0.617 & 1.816 & 0.605 & 0.502 & 0.602 & 0.070 & 0.605 & 0.004 \\
\hline MONEY & 0.565 & 0.605 & 0.620 & $3.066^{*}$ & 0.620 & 2.682 & 0.605 & 0.058 & 0.602 & 0.292 \\
\hline SRVC & 0.559 & 0.141 & 0.620 & 2.225 & 0.617 & 2.145 & 0.623 & 2.380 & 0.608 & 0.032 \\
\hline AGRIC & 0.478 & 0.358 & 0.593 & 1.400 & 0.574 & 0.130 & 0.605 & 1.620 & 0.623 & 1.023 \\
\hline REIT & 0.469 & 0.236 & 0.586 & 0.381 & 0.577 & 0.114 & 0.580 & 1.147 & 0.626 & $2.887^{*}$ \\
\hline NOIND & 0.568 & 0.510 & 0.623 & 2.047 & 0.608 & 0.350 & 0.599 & 0.474 & 0.590 & 0.010 \\
\hline
\end{tabular}

The table reports out-of-sample results for different models including the 34 industry portfolios and also a case where no industries are included (NOIND). Each model includes also $R E_{t-1}, I N F_{t-1}, M D Y_{t-1}, 3 M T H_{t-1}$, and $T S_{t-1}$ as explanatory variables. The reported statistics are the success ratio (12) that tells the percentage of correct forecasts, and the Pesaran and Timmermann (2009) test statistic (14). See also Notes to Table 3.

Table 8 Annual returns and Sharpe ratios of investment strategies using selected models

\begin{tabular}{llccccc}
\hline INDUSTRY & MEASURE & LEVEL & STATIC & DYNAMIC & AUTOREG. & DYNAMIC AR. \\
\hline CNSTR & RETURN & $8.29 \%$ & $12.73 \%$ & $12.08 \%$ & $9.86 \%$ & $8.66 \%$ \\
& SHARPE & 1.17 & 2.12 & 1.98 & 1.44 & 1.08 \\
WOOD & RETURN & $8.26 \%$ & $12.08 \%$ & $11.06 \%$ & $8.89 \%$ & $8.68 \%$ \\
& SHARPE & 1.15 & 1.94 & 1.68 & 1.25 & 1.12 \\
PTRLM & RETURN & $7.50 \%$ & $10.67 \%$ & $11.06 \%$ & $10.79 \%$ & $10.14 \%$ \\
& SHARPE & 0.95 & 1.57 & 1.75 & 1.67 & 1.43 \\
NOIND & RETURN & $9.16 \%$ & $11.60 \%$ & $10.59 \%$ & $9.57 \%$ & $9.28 \%$ \\
& SHARPE & 1.39 & 1.82 & 1.58 & 1.37 & 1.32
\end{tabular}

The table presents annual returns in percentages and ex-post Sharpe ratios (15) for trading strategies based different on forecasting models including selected industry portfolios. Each model includes also $R E_{t-1}, I N F_{t-1}, M D Y_{t-1}, 3 M T H_{t-1}$, and $T S_{t-1}$ as explanatory variables. The trading period is $1986 \mathrm{M} 1-2012 \mathrm{M} 12$. For comparison, the annual return for the buy-and-hold strategy for the period is $9.75 \%$. See also Notes to Table 3 . 
Table 9 In-sample results for daily dynamic probit models with the METAL industry portfolio 1986-2012.

\begin{tabular}{lcccc}
\hline & STATIC & DYNAMIC & AUTOREG. & DYNAMIC AR. \\
\hline CONST & $0.083^{* * *}$ & 0.052 & $0.097^{* * *}$ & 0.064 \\
& $(0.028)$ & $(0.035)$ & $(0.048)$ & $(0.043)$ \\
MET $A L_{t-1}$ & $-0.037^{* * *}$ & $-0.036^{* * *}$ & $-0.037^{* * *}$ & $-0.036^{* * *}$ \\
& $(0.013)$ & $(0.013)$ & $(0.013)$ & $(0.013)$ \\
$R E_{t-1}$ & $0.051^{* *}$ & 0.032 & $0.054^{* *}$ & 0.034 \\
& $(0.021)$ & $(0.023)$ & $(0.021)$ & $(0.024)$ \\
$R F_{t-1}$ & 0.017 & 0.017 & 0.020 & 0.019 \\
& $(0.016)$ & $(0.016)$ & $(0.020)$ & $0.019)$ \\
$y_{t-1}$ & & 0.058 & & 0.062 \\
& & $(0.039)$ & & $(0.039)$ \\
$\pi_{t-1}$ & & & -0.167 & -0.157 \\
& & & $(0.409)$ & $0.235)$ \\
\hline$a d j . p s R^{2}$ & 0.0011 & 0.0012 & 0.0011 & 0.0013 \\
$\log -L$ & -4688.31 & -4687.29 & -4687.62 & -4686.44 \\
$B I C$ & 4705.96 & 4709.36 & 4709.69 & 4712.92 \\
$S R$ & 0.542 & 0.543 & 0.542 & 0.542 \\
$D A$ & 0.323 & 0.620 & 0.426 & 0.093 \\
$P T$ & 0.115 & 0.396 & 0.217 & 0.002 \\
\hline
\end{tabular}

The table reports in-sample results for binary response models used in the study using daily data for 1986-2012, including the METAL industry portfolio as a predictive variable. See also Notes to Table 3. 